\title{
Differential microRNA expression between bone marrow side population cells and hepatocytes in adult mice
}

\author{
YUKI NAGATA ${ }^{1}$, CHIHAYA MAESAWA ${ }^{1}$, HIROSHI TADA ${ }^{1}$, YASUHIRO TAKIKAWA ${ }^{2}$, \\ AKIKO YASHIMA-ABO ${ }^{1}$ and TOMOYUKI MASUDA ${ }^{1}$
}

Departments of ${ }^{1}$ Pathology, ${ }^{2}$ Gastroenterology and Hepatology, School of Medicine, Iwate Medical University, 19-1 Uchimaru, Morioka 020-8505, Japan

Received January 8, 2009; Accepted February 27, 2009

DOI: 10.3892/ijmm_00000203

\begin{abstract}
Hematopoietic stem cells (HSCs) can differentiate into many kinds of parenchymal cells populating several organs. Nevertheless, the differentiation mechanism of HSCs toward hepatocytes remains poorly understood. To identify specific microRNAs (miRNAs) contributing to the mechanism, we investigated the differential expression of miRNAs between side population (SP) cells of bone marrow and hepatocytes in adult mice. We used a miRNA microarray followed by stemloop-mediated reverse transcription real-time PCR to identify 12 SP-specific and 2 hepatocyte-specific miRNAs. Of these, 3 (miR-451, -150 and -223 ) were strongly expressed (>10-fold relative enrichment) in SP cells. Two of these miRNAs (miR-451 and -223) were strongly associated with the hematic cell lineage but not with progenitor characteristics. Twothirds (6/9) of the miRNAs that were moderately expressed in SP cells in comparison with hepatocytes were also upregulated in potential hepatic stem cells (HSCEs). The single miRNA (miRNA-127) that was up-regulated in SP cells compared with lineage-positive bone marrow cells might be an SP marker, since it was markedly down-regulated in HSCEs. These results suggest that SP cells and HSCE share a common profile of miRNA expression and that miRNA-127 may contribute to the maintenance of a quiescent state in SP cells.
\end{abstract}

\section{Introduction}

Regardless of the causative disease (such as viral hepatitis or genetic/autoimmune disorders), end-stage chronic liver disease is an irreversible condition that leads to imminent and complete failure of liver function. In Japan, more than 30,000 people die every year as a result of liver-related disease (1). Whole organ liver, split-liver, and related living donor liver

Correspondence to: Dr Chihaya Maesawa, Department of Pathology, School of Medicine, Iwate Medical University, 19-1 Uchimaru, Morioka 020-8505, Japan

E-mail: chihaya@iwate-med.ac.jp

Key words: SP cell, hepatic stem cell, microRNA, hepatocyte, hematopoietic stem cell transplantation are clinically well-established procedures for the treatment of end-stage liver failure. However, these options are limited by donor organ shortage and the need for lifelong immunosuppressive treatment (2). The development of cell transplant therapy using stem cells would be a major advance in regenerative medicine, and would provide a less invasive procedure for the treatment of chronic liver disease.

Several types of stem cells have been proposed as sources for cell therapy. Embryonic stem cells are the most potent in terms of their differentiation potential, but may be tumorigenic when transplanted in vivo and their use is beset by ethical issues (3). Stem cells are found in many adult tissues (4), of which hematopoietic tissue is the most accessible. In the last decades, many papers have documented that hematopoietic stem cells (HSCs) can differentiate into many kinds of nonhematopoietic cells, such as neuronal tissue, muscle fibers, and hepatocytes (5-8). Such multipotent HSCs are expected to be an ideal source for autologous cell transplant therapy for chronic liver disease. Nevertheless, the mechanism by which HSCs differentiate toward hepatocytes remains poorly understood. Clarification of the mechanism will allow the design of more effective methods to induce such differentiation.

Cell type-specific regulation of gene expression is very important to maintain cellular and/or organ homeostasis. Recently, a type of small non-coding RNA, microRNA (miRNA), has been discovered to play an important role in developmental processes $(9,10)$. Mature miRNAs are 20-22nucleotide molecules that bind to the 3' untranslated region of targeted messenger RNAs. If they bind with imperfect base pairing, translational efficiency is significantly reduced (10). If base pairing is perfect or near-perfect, the targeted mRNA is degraded, providing another regulatory mechanism (11). Specific miRNAs contribute to the differentiation of cell types in many tissues. Examples include miR-142s, -181 and -223 for myeloid differentiation (12), miR-143 targeting Erk5 for adipogenesis (13), and miR-1-1 and -1-2 targeting Hand 2 for cardiac and skeletal muscle formation (14). Thus, we hypothesized that miRNAs may be involved in the differentiation of HSCs toward hepatocytes.

Some investigators have demonstrated the transdifferentiation of marrow-derived cells into hepatocytes in vitro and in vivo, although it remains obscure which subpopulation of these cells is responsible for regeneration $(15,16)$. We selected side population (SP) cells as HSCs in this study, as they are 
an easily accessible component of the stem cell compartment because of their ease of detection and physical isolation by fluorescence-activated cell sorting (FACS). In 1996, Goodell et al (17) reported a new method of obtaining enriched populations of HSCs from adult mouse bone marrow (BM) in a single step. This procedure exploits the ability of HSCs to exclude the fluorescent dye Hoechst 33342 because of the activity of P-glycoprotein (encoded by the multidrug resistance MDR gene) (17). Thus, on FACS analysis, HSCs show a characteristic 'side population' after Hoechst 33342 staining and they disappear when treated with verapamil, which inhibits Hoechst 33342 efflux. SP cells were found to have a CD34Sca- $1^{+}$, and lineage marker-negative phenotype, which has independently been established as an HSC marker in adult mouse BM (18-20). Numerous studies have established that the SP phenotype of HSCs in mice and humans is largely determined by expression of a protein known as the Abcg2 transporter [ATP-binding cassette (ABC) subfamily G member 2, also known as Brcp1] (21-24). In addition, some studies have addressed the ability of cells exhibiting the SP phenotype to regenerate hepatocytes, and consequently cells with the SP phenotype are candidates for cell therapy of chronic liver disease (25-27).

For the development of effective methods to induce HSCs to differentiate into hepatocytes, transcriptome analysis is important and has already been performed (28). However, the miRNA profiles of these cell types have not yet been compared. In this study, we found that several miRNAs are differentially expressed between these cell types. After validation of these miRNAs, we also quantitatively evaluated their expression levels in potential hepatic stem cell (HSCE, likely liver oval cell), because HSCs are thought to be the origin of hepatic oval cells $(15,16)$. Our data support this relationship by showing that the miRNA expression profile of oval cells is similar to that of SP cells.

\section{Materials and methods}

Preparation of BM cells. BM cells were obtained by flushing out the femurs and tibias of 6-12 week-old C57BL/6J male mice (CREA Japan, Inc., Tokyo, Japan). Monocyte and erythrocyte fractions were separated by using HISTPAQUE 1083 (Sigma, St. Louis, MO, USA) and centrifuged at $1,200 \mathrm{rpm}$ for $20 \mathrm{~min}$ at $4^{\circ} \mathrm{C}$. Monocytes were incubated with $5 \mu \mathrm{g} / \mathrm{ml}$ of Hoechst 33342 (Sigma) in Hank's buffered salt solution (HBSS; Invitrogen Corp., Carlsbad, CA, USA) containing $2 \%$ fetal bovine serum (FBS, Invitrogen) and $1 \%$ penicillin/streptomycin (Sigma) for $1 \mathrm{~h}$ at $37^{\circ} \mathrm{C}$. To prepare SP cells, we initially stained cells with Hoechst 33342. To identify the side population, a portion of the Hoechst 33342stained cells was treated with $100 \mu \mathrm{l} / \mathrm{ml}$ verapamil (Sigma). The cells were washed and resuspended in phosphate-buffered saline (PBS) at $1 \times 10^{8}$ cells $/ \mathrm{ml}$ and stained with biotin-labeled lineage marker antibody cocktail [recognizing Cd11b (cat. no. 553309), Gr-1 (cat. no. 553125), CD45R/B220 (cat. no. 553086), Cd4 (cat. no. 553649), Cd8a (cat. no. 553028) and TER-119 (cat. no. 553672); all from BD Biosciences, San Jose, CA, USA] on ice for $30 \mathrm{~min}$. Then, the cells were washed and resuspended in PBS, followed by staining with streptavidin-phycoerythrin (PE)-Cy5 (BD Biosciences; cat. no. 554062) and resuspension in PBS at $2 \times 10^{7}$ cells $/ \mathrm{ml}$. After addition of $500 \mu \mathrm{M}$ of PI (propidium iodide, Sigma), cells were passed through a cell strainer (BD Biosciences) to exclude duplet cells and kept on ice for analysis in a FACSAria (BD Biosciences). Lineage-negative and viable SP cells were harvested. At the same time, lineage-negative and viable non-SP cells were also collected.

For the sorting of lineage-positive cells, we first stained monocytes with biotin-labeled lineage marker antibody cocktail (BD Biosciences; see above) and then we used streptavidinPE (phycoerythrin)-Cy7 (BD Biosciences; cat. no. 557598) for the second staining. Before sorting, cells were stained with $500 \mu \mathrm{M}$ PI and then the PI-negative/PE-Cy-7 positive fraction was collected as lineage-positive cells. Similarly, immature erythrocyte cells, granulocytes, B- and T-cells were collected after staining with biotin-labeled Ter-119, Gr-1, CD45R/B220 and Cd4 antibodies, respectively. PE-Cy7 was used as second antibody.

Preparation of hepatocytes and HSCEs. We purchased the primary culture of hepatocytes from Primary Cell Co. Ltd. (Hokkaido, Japan). C57BL/6J mice (8 weeks old) were used for hepatocyte preparation as described by Bumgardner et al (29). Cultured HSCEs were kindly provided by Dr M. Tanaka (Institute of Molecular and Cellular Biosciences, University of Tokyo, Tokyo, Japan). These cells were used to identify miRNAs differentially expressed between SP cells and hepatocytes.

RNA isolation. We used a miRNeasy kit (Qiagen, Cologne, Germany) and/or TRIzol reagent (Invitrogen) to isolate RNAs from 7 sorted fractions [SP, non-SP, each fraction positive for a lineage marker (Ter-119, Gr-1, Cd4 and CD45R/B220), and a crude sample containing all lineage marker-positive cells] and a fraction of anucleated erythrocytes from BM. RNAs were extracted from HSCEs with TRIzol reagent (Invitrogen).

miRNA microarray analysis. We examined global miRNA expression by an miRNA microarray system using digoxygenin (dig)-labeled locked nucleic acid (LNA)-oligonucleotides (B-Bridge International, Inc., Tokyo, Japan). Briefly, $5 \mu \mathrm{g}$ of total RNA was exposed to the miRCURY version 8.0 array panel (294 miRNAs; Exiqon, Vedbaek, Denmark). The signal values of spike controls were averaged and used as a cut-off value, and sample probes which were under the cut-off value were excluded. Then SP/hepatocyte (SP-specific) and hepatocyte/SP (hepatocyte-specific) ratios were calculated (Table I). A 3-fold increase was considered to characterize miRNAs specific to SP cells or hepatocytes.

Real-time PCR. We used a stem-loop-mediated reverse transcription real-time PCR method (TaqMan MicroRNA Assay; Applied Biosystems, ABI, Foster City, CA, USA) in accordance with the manufacturer's instructions. Expression levels of miRNAs were analyzed with an ABI PRISM 7500 instrument. Experiments were performed more than three times ( 2 samples included in each experiment), and mean values and their standard deviations are presented (Table II). Rnu6 was used as an internal control with the following 
Table I. Microarray data for SP- and hepatocyte-specific miRNAs.

\begin{tabular}{|c|c|}
\hline miRNA & Average change (-fold) \\
\hline \multicolumn{2}{|c|}{ SP-specific miRNAs } \\
\hline miR-92 & 8.55 \\
\hline miR-328 & 7.23 \\
\hline miR-212 & 6.26 \\
\hline miR-331 & 5.73 \\
\hline $\operatorname{miR}-20 b$ & 5.27 \\
\hline $\operatorname{miR}-191$ & 4.39 \\
\hline $\operatorname{miR}-15 b$ & 4.23 \\
\hline $\operatorname{miR}-207$ & 4.20 \\
\hline $\operatorname{miR}-223$ & 4.18 \\
\hline $\operatorname{miR}-451$ & 4.09 \\
\hline $\operatorname{miR}-30 a-5 p$ & 3.76 \\
\hline $\operatorname{miR}-221$ & 3.67 \\
\hline miR-30d & 3.48 \\
\hline $\operatorname{miR}-325$ & 3.47 \\
\hline $\operatorname{miR}-30 \mathrm{e}$ & 3.24 \\
\hline $\operatorname{miR}-466$ & 3.13 \\
\hline $\operatorname{miR}-127$ & 3.08 \\
\hline miR-181a & 3.08 \\
\hline $\operatorname{miR}-16$ & 3.06 \\
\hline miR-199a & 3.01 \\
\hline miR-183 & 3.01 \\
\hline miR-150 & 3.01 \\
\hline \multicolumn{2}{|c|}{ Hepatocyte-specific miRNAs } \\
\hline miR-122a & 50.0 \\
\hline miR-542-5p & 33.3 \\
\hline miR-140 & 9.09 \\
\hline $\operatorname{miR}-374-5 p$ & 7.69 \\
\hline miR-146 & 7.14 \\
\hline $\operatorname{miR}-292-5 p$ & 5.00 \\
\hline miR-301 & 3.57 \\
\hline miR-351 & 3.13 \\
\hline
\end{tabular}

primer/probe set: 5'-TGG AAC GAT ACA GAG AAG ATT AGCA-3' (forward) and 5'-AAC GCT TCA CGA ATT TGC GT-3' (reverse); probe, 5'-FAM-CCC CTG CGC AAG GAMGB-3'. The expression of each miRNA relative to Rnu6 was determined by the ddCt method. The threshold cycle $(\mathrm{Ct})$ was defined as the fractional cycle number at which the fluorescence passed a fixed threshold. Average fold differences were calculated by normalizing the relative expression $(\mathrm{ddCt}$ values) according to ABI User Bulletin \#2.

Conventional real-time quantitative RT-PCR was also performed with the ABI system. For quantification of Abcg2 transporter mRNA, 5'-GGA GGC AAG TCT TCG TTG CT-3' (forward) and 5'-AAA TGG GCA GGT TGA GGT G-3' (reverse); probe, 5'-FAM-CTT AGC AGC AAG GAA AGAT CCA AAG GGA-TAMRA-3' were used. Rodent GAPDH primer/probe set (ABI) was used as an internal control.
Table II. Results of real-time PCR for SP- and hepatocytespecific miRNAs.

\begin{tabular}{|c|c|c|}
\hline miRNA & $\begin{array}{l}\text { Average change } \\
\quad(- \text { fold })\end{array}$ & SD \\
\hline \multicolumn{3}{|c|}{ SP-specific miRNAs } \\
\hline miR-92 & 5.10 & 1.81 \\
\hline miR-328 & 0.59 & 0.18 \\
\hline miR-212 & 180.43 & 355.95 \\
\hline $\operatorname{miR}-331$ & 0.58 & 0.68 \\
\hline miR-20b & 6.49 & 4.21 \\
\hline miR-191 & 2.49 & 3.24 \\
\hline $\operatorname{miR}-15 b$ & 3.39 & 2.57 \\
\hline miR-207 & 17.83 & 8.67 \\
\hline $\operatorname{miR}-223$ & 56.56 & 26.87 \\
\hline $\operatorname{miR}-451$ & 481.64 & 92.50 \\
\hline miR-30a-5p & 0.51 & 0.23 \\
\hline $\operatorname{miR}-221$ & 2.38 & 1.11 \\
\hline miR-30d & 0.41 & 0.30 \\
\hline miR-325 & 9.31 & 3.94 \\
\hline miR-30e & 0.08 & 0.10 \\
\hline $\operatorname{miR}-466$ & 4.86 & 1.26 \\
\hline miR-127 & 6.00 & 4.69 \\
\hline miR-181a & 12.88 & 2.30 \\
\hline $\operatorname{miR}-16$ & 0.33 & 0.29 \\
\hline $\operatorname{miR}-199 a$ & ND & \\
\hline miR-183 & ND & \\
\hline miR-150 & 154.24 & 72.24 \\
\hline \multicolumn{3}{|c|}{ Hepatocyte-specific miRNAs } \\
\hline miR-122 & 113.10 & 173.56 \\
\hline $\operatorname{miR}-542-5 p$ & 0.21 & 0.17 \\
\hline $\operatorname{miR}-140$ & 1.82 & 1.23 \\
\hline $\operatorname{miR}-374-5 p$ & 0.34 & 0.24 \\
\hline $\operatorname{miR}-146$ & 7.91 & 4.56 \\
\hline $\operatorname{miR}-292-5 p$ & ND & \\
\hline miR-301 & 0.52 & 0.22 \\
\hline miR-351 & 1.20 & 1.80 \\
\hline
\end{tabular}

$\mathrm{SD}$, standard deviation; ND, not done.

Semi-quantitative RT-PCR. HSCE phenotype was validated by semi-quantitative RT-PCR. Hepatocyte or HSCE total RNAs (5 $\mu \mathrm{g}$ each) were reverse transcribed with HighCapacity cDNA Archive Kit (ABI). The PCR reaction was performed with AmpliTaq Gold PCR Master Mix (ABI) and GeneAmp PCR System 9700 (ABI), and 500 ng of cDNA was amplified by semi-quantitative PCR. mRNA expressions of Alb (albumin), Afp ( $\alpha$-fetoprotein), Krt18 (cytokeratin-18, liver cell skeletal gene), Krt19 (cytokeratin-18, biliary marker) and Actb (B-actin, loading control) were tested with primer sets as follows: Alb, forward 5'-CTC AGG TGT CAA CCC CAA-3', reverse 5'-TCC ACA CAA GGC AGT CTC-3'; Afp, forward 5'-GTG AAA CAG ACT TCC TGG TCC T-3', 
reverse 5'-GCC CTA CAG ACC ATG AAA CAA G-3'; Krt18, forward 5'-TGG TAC TCT CCT CAA TCT GCTG-3', reverse 5'-CTC TGG ATT GAC TGT GGA AGT G-3'; Krt19, forward 5'-CAT GGT TCT TCT TCA GGT AGG C-3', reverse 5'-CCA AGA CTT ACG TAG ACG TCG-3'; Actb, forward 5'-CCA AGG CCA ACC GCG AGA AGA TGA C-3', reverse 5'-AGG GTA CAT GGT GGT GCC GCC AGA C-3'. The following reaction conditions were used: denaturation at $94^{\circ} \mathrm{C}$ for $30 \mathrm{sec}$, annealing at $60^{\circ} \mathrm{C}$ for $1 \mathrm{~min}$, extension at $72^{\circ} \mathrm{C}$ for $1 \mathrm{~min}$ and final extension at $72^{\circ} \mathrm{C}$ for $5 \mathrm{~min}$. PCR cycles were 35 for Alb and Krt18, 30 for Krt19 and Afp, and 25 for Actb. The amplified products were subjected to electrophoresis in $1 \%$ agarose gels and stained with ethidium bromide.

\section{Results}

Detection by miRNA microarray of miRNAs differentially expressed between BM SP cells and hepatocytes. To identify miRNAs differentially expressed between SP cells and hepatocytes, we sorted SP cells from BM (Fig. 1A). To confirm the SP phenotype, cells were incubated with Hoechst 33342 and verapamil (Fig. 1B). Verapamil is a transporter inhibitor that is able to block Hoechst dye exclusion from SP cells. Abcg2 mRNA expression of the SP cell fraction was increased more than 3-fold in comparison with that of the non-SP fraction (Fig. 1C). In miRNA microarray analysis, 22 SP-specific and 8 hepatocyte-specific miRNAs exhibited more than a 3 -fold increase (semi-quantitative analysis for miRNA expression; SP vs hepatocyte, Table I).

Next, we validated these miRNAs by stem-loop-mediated reverse transcription real-time PCR (Fig. 2). Six of the 22 SPspecific miRNAs (miR-212, -331, -191, -30e, -199 and -183) and 2 of the 8 hepatocyte-specific miRNAs (miR-351 and $-292-5 p$ ) exhibited a wide range of measurements (standard deviations exceeded their mean value) or were not detected by this method (Table II). Such discrepancies may depend on the design of primer/probe sets or other unexpected factors. Therefore, we excluded these miRNAs from further examination. miR-122 has been reported to be a hepatocyte-specific miRNA $(30,31)$. In our real-time PCR analysis, values for miR-122 also exhibited a large standard deviation exceeding the mean value. However, this arose from the fact that BM SP cells expressed extremely low amounts of miR-122 that were difficult to measure reproducibly (Fig. 2C). Exceptionally, therefore, we included miR-122 as a hepatocyte-specific miRNA. Data for the validated miRNAs (12 SP-specific and 2 hepatocyte-specific miRNAs) from real-time PCR analysis are summarized in Table III. The degree of expression was categorized as follows: $>10$-fold enrichment, strongly expressed; >2-fold enrichment, moderately expressed.

Cell type-specific miRNA expression may play important roles in cellular maturation toward terminal differentiation and in the maintenance of cellular characteristics such as progenitor potential. miRNAs that are differentially expressed between BM SP cells and hepatocytes are potentially factors in the regulation of transdifferentiation from HSCs to hepatocytes, and such factors would be key molecules in the development of autologous cell transplant therapy in chronic liver disease. We further investigated the expression of the identified
A

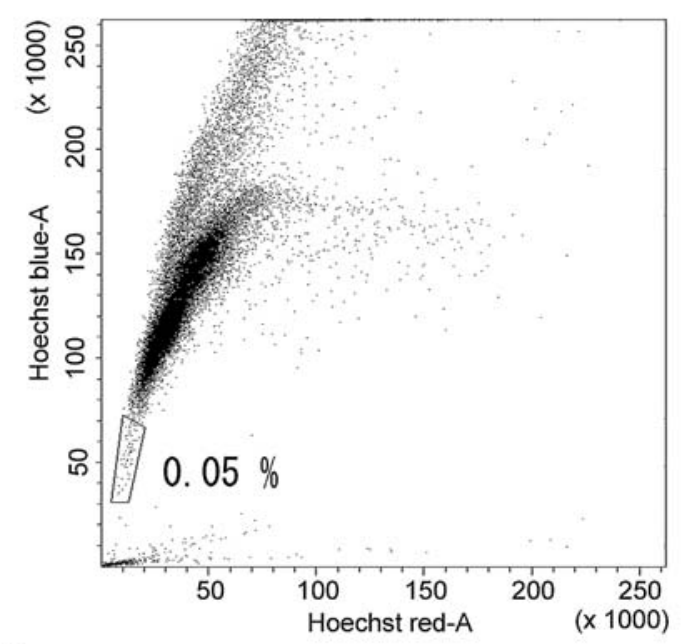

B
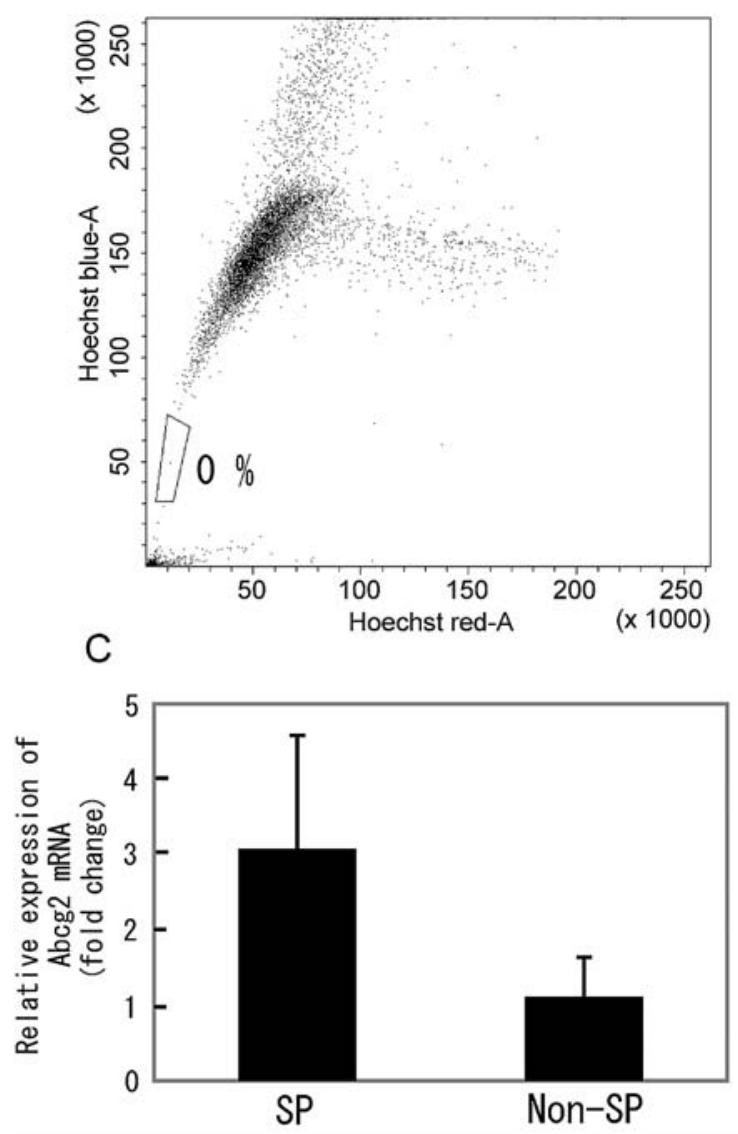

Figure 1. Sorting of SP cells by FACSAria. (A), Prepared cells were expanded to Hoechst-blue and Hoechst-red, and the SP population ( $0.05 \%$ of BM cells) was gated and collected. (B), The SP population disappeared after verapamil treatment. (C), The SP phenotype was validated by the expression level of Abcg2 transporter mRNA. Results indicate the -fold change of Abcg2 transporter mRNA expression in comparison with that of lineage-positive cells (see Materials and methods).

candidate miRNAs in cells of hematopoietic lineages and in cultured HSCEs, which may be liver progenitor cells.

Strongly expressed SP-specific miRNAs in BM cells. Three miRNAs (miR-451, -150 and -223) that were strongly 


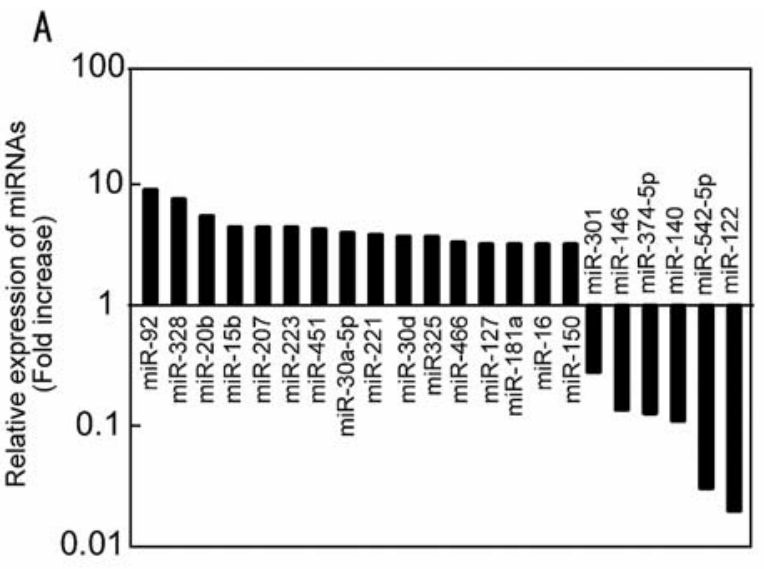

B
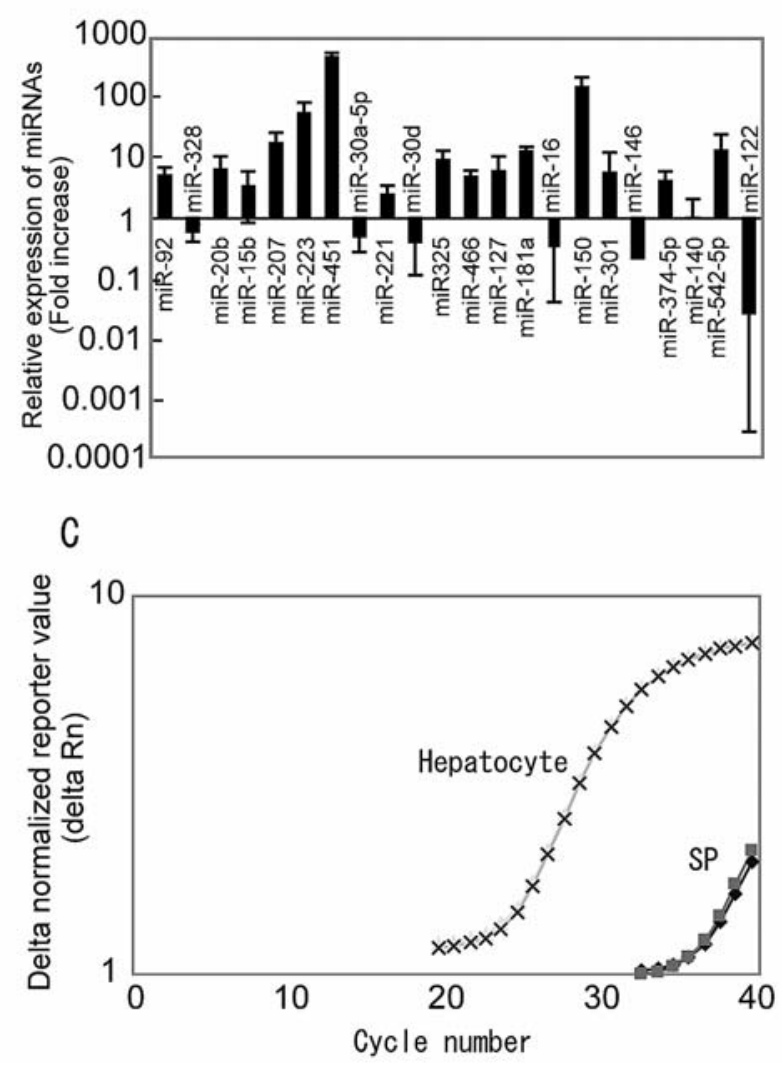

Figure 2. SP- and hepatocyte-specific miRNA expression detected by microarray (A) and real-time PCR (B and C). The miRNAs listed in Table II were analyzed by real-time PCR at least three times, and are arranged by extent of -fold change. Each SP- or hepatocyte-specific miRNA value was calculated by normalizing the relative expression (dCt values) using the value for the other cell type. Average and standard deviation are shown (B). Amplification plots of miR-122 in SP cells and hepatocytes (C). Hepatocytes strongly express miR-122 but SP cells do not. Total RNA (1 ng) was amplified.

expressed in SP cells have already been reported to be maturation factors in their respective hematic cell lineages (32-34). Dynamic changes in the expression of these miRNAs contribute to the regulation of key molecules (such as transcription factors) during the maturation process of each lineage (32-34). To confirm these reports, we compared the expression levels of these miRNAs between SP cells and other types of hematic cells fractionated from BM (Fig. 3).

First, we examined miR-451 expression in SP, non-SP and Ter-119-positive (containing mature erythrocytes and
Table III. Cell type-specific miRNAs.

\begin{tabular}{llc}
\hline & SP-specific & Hepatocyte-specific \\
\hline Strongly expressed & miR-451 & miR-122 \\
& miR-150 & \\
miR-223 & \\
Moderately expressed & miR-207 & miR-146 \\
& miR-181a & \\
& miR-325 & \\
& miR-20b & \\
& miR-127 & \\
& miR-92 & \\
& miR-466 & \\
& miR-15b & \\
& miR-221 & \\
\hline
\end{tabular}

pre-erythrocytes) cells and in red blood cells (containing anucleated mature erythrocytes) in comparison with lineagepositive cells (see Materials and methods), because miR-451 has been reported to be an erythrocyte-specific miRNA (32). In SP cells, miR-451 showed 3.80-fold expression compared with lineage-positive cells. Non-SP cells, Ter-119-positive cells and erythrocytes showed $0.20-, 4.76-$ and 141.60 -fold increases in expression, respectively, compared with lineage-positive cells (Fig. 3A). Next, we examined miR-150 expression in SP cells, non-SP cells, CD45R/B220-positive cells and CdD4-positive cells compared with lineage-positive cells, because miR-150 has been reported to be a B- and T-cellspecific miRNA (33). CD45R/B220 and Cd4 are surface markers for the B- and T-cell lineages, respectively. Non-SP cells, CD45R/B220-positive cells and Cd4-positive cells showed more than 2-fold expression compared with SP, but the difference was not significant (Fig. 3C). miR-223 has been reported to be a granulocyte-specific miRNA (34), and therefore we examined miR-223 expression in SP cells, nonSP cells and Gr-1 positive cells, containing the granulocytic population, compared with lineage-positive cells (Fig. 3C). The dynamic changes in miR-223 expression resembled those of miR-451 expression. This valley-like change of miRNA expression could be explained by the 'promiscuous beginning' model (35) (see Discussion). In this model, stem cells express certain lineage-specific genes required for subsequent unique lineage determination, making provision for future differentiation. Once cell fate is committed, lineage-specific genes are increased and others are decreased. However, we did not observe a valley-like pattern of miR-150 expression (Fig. 3B).

Candidate miRNA markers for HSCs as progenitor cells. To identify miRNAs that might be markers for HSCs, we examined expression of the miRNAs listed in Table III between SP and lineage-positive cells of BM. As mentioned above, there was not a marked increase ( $>4$-fold) in 3 strongly expressed miRNAs (miR-451,-150 and -223) in comparison with lineage-positive cells (Fig. 3) and HSCEs (data not shown). Thus, these 3 miRNAs might be lineage determination 


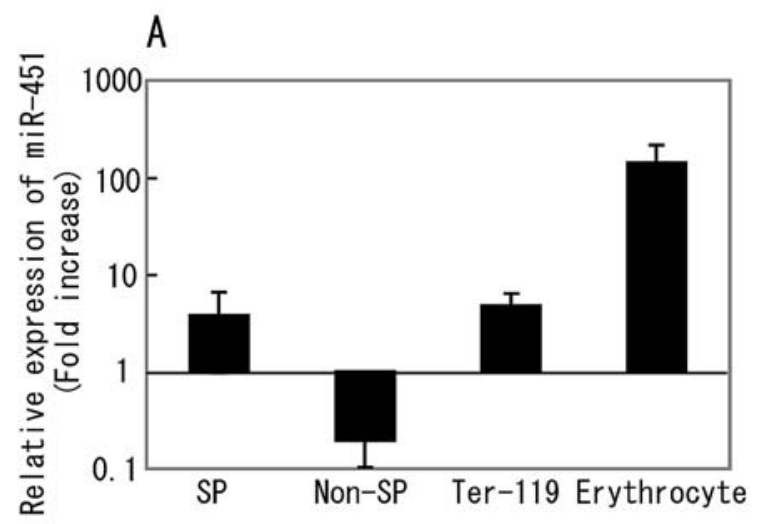

B

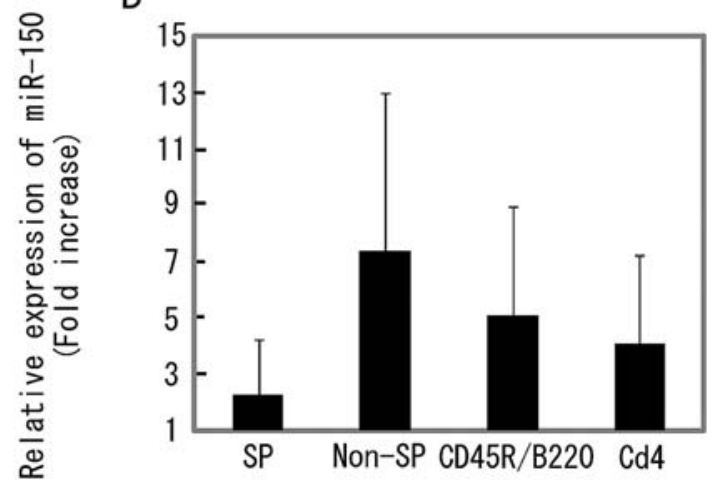

C

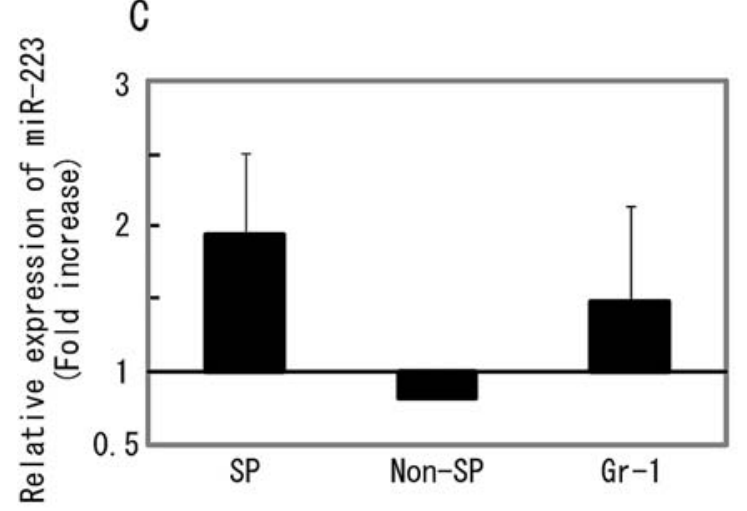

Figure 3. Expression levels of strongly expressed SP-specific miRNAs in hematic cells. (A), miR-451 expression in SP cells, non-SP cells, Ter-119 positive cells and erythrocytes compared with that in lineage-positive cells. (B), miR-150 expression in SP cells, non-SP cells, B220 positive cells (B-cells) and CD4 positive cells (T-cells) compared with that in lineage-positive cells. (C), miR-223 expression in SP cells, non-SP cells and Gr-1 positive (granulocyte) cells. Values were calculated by normalizing to the relative expression ( $\mathrm{dCt}$ values) of lineage-positive cells. Average and standard deviation are shown.

markers, but not markers of HSCs as progenitor cells. Conversely, 3 of the 9 moderately expressed miRNAs showed a $>4$-fold increase in SP cells (miR-207, -325 and -127) (Fig. 4A). Of these, miR-127 was strongly increased (>8-fold) in SP cells in comparison with lineage-positive cells of BM (Fig. 4A). These up-regulated miRNAs might be required for the maintenance of progenitor potential in HSCs. We further evaluated the expression of these miRNAs in cultured HSCEs, which may be liver progenitor cells.

Hepatocyte-specific miRNAs. The results of semi-quantitative RT-PCR analysis for mRNAs unique to HSCEs $\left(\mathrm{Alb}^{+}, \mathrm{Afp}^{+}\right.$,
Ck-18+ and $\mathrm{Ck}-19^{+}$) were compatible with previous reports $(36,37)$ (Fig. 4B). We then examined relative miRNA expression in BM SP cells and cultured HSCEs. Marked downregulation of miR-122 was observed in cultured HSCEs in comparison with hepatocytes (Fig. 4C), while that of miR-146 was not changed. Interestingly, 3 (miR-207, -325 and -127) of the 9 miRNAs that were moderately expressed in SP cells in comparison with lineage-positive cells of BM were markedly down-regulated in HSCEs. In particular, miR-127 exhibited marked down-regulation in comparison with SP cells (Fig. 4D). We discuss differences in miRNA expression profiles between BM SP cells and HSCEs, and the significance of miR-127 down-regulation in HSCEs, below.

\section{Discussion}

In the present study, we identified 14 miRNAs that are differentially expressed between SP cells of BM and hepatocytes. Three (miR-451, -150 and -223) of these 14 miRNAs are lineage determination markers for hematopoietic cells, as previously described (32-34). When we compared the expression of these miRNAs in SP cells, non-SP cells and differentiated erythrocytes or granulocytes with that in lineagepositive cells, we found that expression was reduced only in non-SP cells. That is, these miRNAs were expressed in stem cells (SP), down-regulated in lineage-negative cells (non$\mathrm{SP}$ ), then expressed again in terminal differentiated cells (erythrocytes or granulocytes). This phenomenon, which has already been described in Results, could be explained by the 'promiscuous beginning' model of Enver and Greaves $(28,29)$. In this model, stem cells express some of the lineage-specific genes required for subsequent unique lineage determination, making provision for future differentiation (Fig. 5). Once cell fate is committed, expression of lineage-specific genes is increased and that of other genes is decreased (Fig. 5). The 'promiscuous beginning' model was suggested for mRNA expression, and it will be interesting to study whether this model is also applicable to miRNA expression.

It has already been described that miR-122 contributes to down-regulation of a cationic amino acid transporter (38) and to up-regulation of replication of hepatitis $C$ virus in the liver (30). This hepatocyte-specific miRNA has been intensively studied because of its potential importance in antiviral therapy. However, the functional significance of miR-146 in the liver has remained uncertain.

The interesting miRNAs underlying transdifferentiation from HSCs to hepatocytes appear to fall into the class of moderately expressed SP-specific miRNAs rather than strongly expressed ones. Six out of 9 moderately expressed SP-specific miRNAs exhibited up-regulation not only in BM SP cells but also in HSCEs in comparison with mature hepatocytes. HSCEs are believed to have the ability to expand clonally and possess a bipotential capacity, which allows them to differentiate into both hepatocytes and bile duct epithelial cells (39). This cell type plays an important role in liver regeneration under certain physiologic conditions (39), but its origin has been controversial. Initially, HSCEs were believed to originate in the liver within the canals of Hering (39). Later, Petersen et al (8) reported that BM cells were a potential source of HSCEs, whereas several reports suggested that BM progenitors are 
A

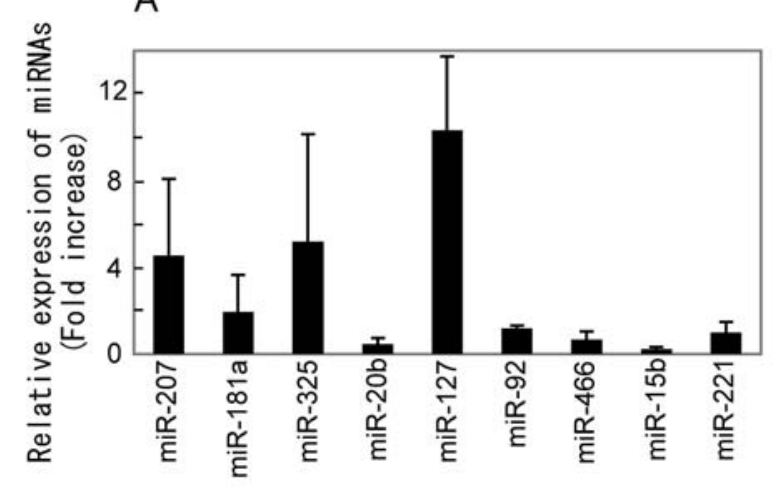

B

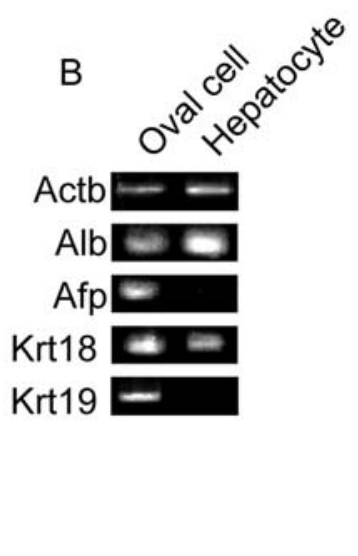

C

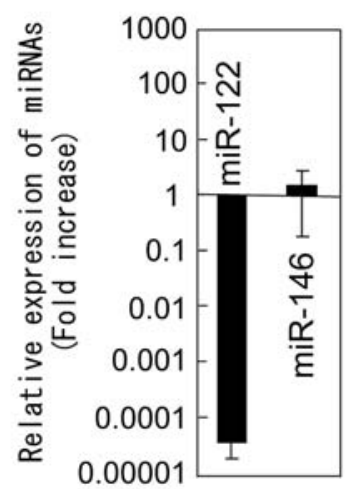

D

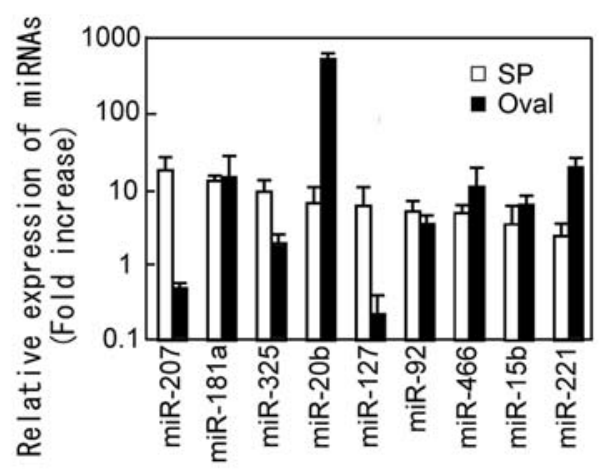

Figure 4. SP- and hepatocyte-specific miRNA expression in SP and HSCEs. (A), Expression level of 9 moderately expressed SP-specific miRNAs in SP cells compared with lineage-positive BM cells. A >4-fold increase was observed in 3 miRNAs (miR-207, -325 and -127). (B), Validation of HSCE phenotype by semi-quantitative real-time PCR. Alb, albumin; Afp, $\alpha$-fetoprotein; Krt18, cytokeratin-18 (liver cell skeletal gene); Krt19, cytokeratin-19 (biliary marker); Actb, B-actin (loading control). (C), miR-122 and -146 expression levels in HSCEs compared with those in hepatocytes. (D), Expression levels of 9 moderately expressed SP-specific miRNAs in SP cells and HSCEs compared with those in hepatocytes.
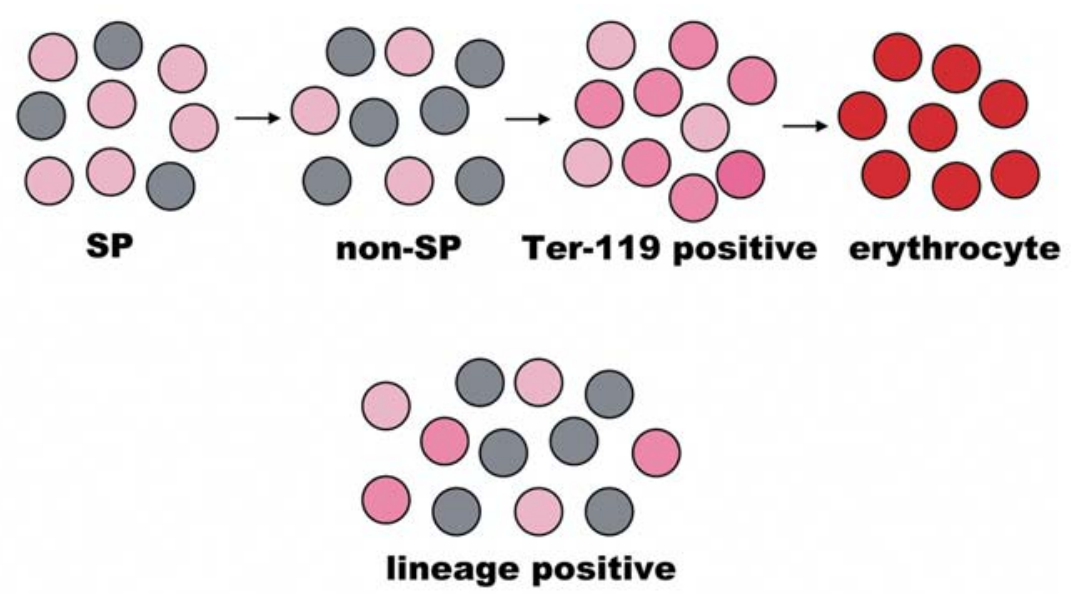

no expression of $\mathrm{miR}-451$

weak expression of miR-451

moderate expression of miR-451

strong expression of $\mathbf{m i R}-451$

Figure 5. The 'promiscuous beginning' model in erythrocyte differentiation. In this model, some SP cells express miR-451 (shown as light pink ball). Once cell fate is committed, lineage-specific genes are increased and others are decreased, so some non-SP cells shut off miR-451 expression (shown as gray ball). During differentiation into erythrocytes, miR-451 expression increases in parallel with erythrocyte maturation (shown as dark pink and red). 
not the source of expanding HSCEs in injured liver because cell fusion (hepatocyte-monocyte) has frequently been observed there (40). However, Oh et al (41) have recently demonstrated that HSCEs might originate from BM and can differentiate into hepatocytes. They used an elegant model in which proliferation of endogenous hepatocytes or resident HSCEs was inhibited by the administration of mitotic inhibitor. Other reports have supported the idea that HSCEs are derived from progenitor cells of the BM $(42,43)$.

The idea that HSCEs originate from BM HSCs is supported by the observation that HSCEs exhibit a similar pattern of miRNA expression to that of BM SP cells [two-thirds (6/9) of the miRNAs that are up-regulated in SP cells in comparison with lineage-positive BM cells]. In addition, in silico analysis suggested that one of the 3 such miRNAs (miR-207, -325 and -127) that showed a different expression pattern in HSCEs compared with SP cells might contribute to acquisition of proliferative activity in HSCEs. miR-127 is known to target the proto-oncogene BCL6 (44). BCL6 can inhibit the antiproliferative function of the p19 ARF-p53 signaling pathway and immortalize the cells, similar to the cancer cell phenotype (45). SP cells are known to be in quiescent phase (46), and Hatfield et al (47) indicated that miRNAs are important for enabling stem cells to overcome the G1/S checkpoint of the cell cycle. Thus, miR-127 possibly maintains the quiescent state by blocking translation of BCL6 in progenitor cells. The receipt of differentiation signals by HSCEs may cause a decrease in miR-127 levels, releasing them from a quiescent state to actively proliferate and differentiate. Moreover, a database search (miRBase; http://microrna.sanger.ac.uk/) also suggested the possibility that miR-207 might targeting Ctf18-replication factor C, which regulates the cell cycle (48). Nevertheless, miR-127 and -207 have many other candidate targets besides BCL6 and Ctf18, and they may modulate another pathway and/or another target in both SP cells and HSCEs. Further studies are required to reveal the precise function of these miRNAs in these cell types during liver regeneration.

\section{Acknowledgements}

This work was supported, in part, by Grants-in-Aid for Scientific Research (19591558, 19591599, 19590363, 19790267 and 19591941) from the Ministry of Education, Science, Sports and Culture of Japan (MEXT), and the 'Open Research Center' Project from MEXT, 2004-2008.

\section{References}

1. Kogure T, Ueno Y, Kawagishi N, et al: The model for end-stage liver disease score is useful for predicting economic outcomes in adult cases of living donor liver transplantation. J Gastroenterol 41: 1005-1010, 2006.

2. Keeffe EB: Liver transplantation: current status and novel approaches to liver replacement. Gastroenterology 120: 749-762, 2001.

3. Shenfield F: Semantics and ethics of human embryonic stemcell research. Lancet 365: 2071-2073, 2005.

4. Preston SL, Alison MR, Forbes SJ, Direkze NC, Poulsom R and Wright NA: The new stem cell biology: something for everyone. Mol Pathol 56: 86-96, 2003.

5. Brazelton TR, Rossi FM, Keshet GI and Blau HM: From marrow to brain: expression of neuronal phenotypes in adult mice. Science 290: 1775-1779, 2000
6. Ferrari G, Cusella-De Angelis G, Coletta M, et al: Muscle regeneration by bone marrow-derived myogenic progenitors. Science 279: 1528-1530, 1998.

7. Mezey E, Chandross KJ, Harta G, Maki RA and McKercher SR: Turning blood into brain: cells bearing neuronal antigens generated in vivo from bone marrow. Science 290: 1779-1782, 2000.

8. Petersen BE, Bowen WC, Patrene KD, et al: Bone marrow as a potential source of hepatic oval cells. Science 284: 1168-1170, 1999.

9. Lee RC, Feinbaum RL and Ambros V: The C. elegans heterochronic gene lin-4 encodes small RNAs with antisense complementarity to lin-14. Cell 75: 843-854, 1993.

10. Olsen PH and Ambros V: The lin-4 regulatory RNA controls developmental timing in Caenorhabditis elegans by blocking LIN-14 protein synthesis after the initiation of translation. Dev Biol 216: 671-680, 1999.

11. Rhoades MW, Reinhart BJ, Lim LP, Burge CB, Bartel B and Bartel DP: Prediction of plant microRNA targets. Cell 110: 513-520, 2002.

12. Chen CZ, Li L, Lodish HF and Bartel DP: MicroRNAs modulate hematopoietic lineage differentiation. Science 303: 83-86, 2004.

13. Esau C, Kang X, Peralta E, et al: MicroRNA-143 regulates adipocyte differentiation. J Biol Chem 279: 52361-52365, 2004.

14. Zhao Y, Samal E and Srivastava D: Serum response factor regulates a muscle-specific microRNA that targets Hand2 during cardiogenesis. Nature 436: 214-220, 2005.

15. Corcelle V, Stieger B, Gjinovci A, Wollheim CB and Gauthier BR: Characterization of two distinct liver progenitor cell subpopulations of hematopoietic and hepatic origins. Exp Cell Res 312: 2826-2836, 2006.

16. Kallis YN, Alison MR and Forbes SJ: Bone marrow stem cells and liver disease. Gut 56: 716-724, 2007.

17. Goodell MA, Brose K, Paradis G, Conner AS and Mulligan RC: Isolation and functional properties of murine hematopoietic stem cells that are replicating in vivo. J Exp Med 183: 1797-1806, 1996.

18. Osawa M, Hanada K, Hamada H and Nakauchi H: Long-term lymphohematopoietic reconstitution by a single CD34-low/ negative hematopoietic stem cell. Science 273: 242-245, 1996.

19. Spangrude GJ, Smith L, Uchida N, et al: Mouse hematopoietic stem cells. Blood 78: 1395-1402, 1991.

20. Miller CL and Eaves CJ: Expansion in vitro of adult murine hematopoietic stem cells with transplantable lympho-myeloid reconstituting ability. Proc Natl Acad Sci USA 94: 13648-13653, 1997.

21. Scharenberg CW, Harkey MA and Torok-Storb B: The ABCG2 transporter is an efficient Hoechst 33342 efflux pump and is preferentially expressed by immature human hematopoietic progenitors. Blood 99: 507-512, 2002.

22. Kim M, Turnquist $\mathrm{H}$, Jackson $\mathrm{J}$, et al: The multidrug resistance transporter ABCG2 (breast cancer resistance protein 1) effluxes Hoechst 33342 and is overexpressed in hematopoietic stem cells. Clin Cancer Res 8: 22-28, 2002.

23. Zhou S, Morris JJ, Barnes Y, Lan L, Schuetz JD and Sorrentino BP: Bcrp1 gene expression is required for normal numbers of side population stem cells in mice, and confers relative protection to mitoxantrone in hematopoietic cells in vivo. Proc Natl Acad Sci USA 99: 12339-12344, 2002.

24. Guo Y, Lubbert M and Engelhardt M: CD34- hematopoietic stem cells: current concepts and controversies. Stem Cells 21: 15-20, 2003.

25. Hussain SZ, Strom SC, Kirby MR, et al: Side population cells derived from adult human liver generate hepatocyte-like cells in vitro. Dig Dis Sci 50: 1755-1763, 2005.

26. Wulf GG, Luo KL, Jackson KA, Brenner MK and Goodell MA: Cells of the hepatic side population contribute to liver regeneration and can be replenished with bone marrow stem cells. Haematologica 88: 368-378, 2003.

27. Uchida N, Fujisaki T, Eaves AC and Eaves CJ: Transplantable hematopoietic stem cells in human fetal liver have a CD34(+) side population (SP) phenotype. J Clin Invest 108: 1071-1077, 2001.

28. Rochon C, Frouin V, Bortoli S, et al: Comparison of gene expression pattern in SP cell populations from four tissues to define common 'stemness functions'. Exp Cell Res 312: 2074-2082, 2006.

29. Bumgardner GL, Gao D, Li J, Baskin JH, Heininger M and Orosz CG: Rejection responses to allogeneic hepatocytes by reconstituted $\mathrm{SCID}$ mice, $\mathrm{CD} 4, \mathrm{KO}$, and $\mathrm{CD} 8 \mathrm{KO}$ mice. Transplantation 70: 1771-1780, 2000. 
30. Jopling CL, Yi M, Lancaster AM, Lemon SM and Sarnow P: Modulation of hepatitis $\mathrm{C}$ virus RNA abundance by a liverspecific microRNA. Science 309: 1577-1581, 2005

31. Krutzfeldt J, Rajewsky N, Braich R, et al: Silencing of microRNAs in vivo with 'antagomirs'. Nature 438: 685-689, 2005.

32. Masaki S, Ohtsuka R, Abe Y, Muta K and Umemura T: Expression patterns of microRNAs 155 and 451 during normal human erythropoiesis. Biochem Biophys Res Commun 364: 509-514, 2007

33. Zhou B, Wang S, Mayr C, Bartel DP and Lodish HF: miR-150, a microRNA expressed in mature $\mathrm{B}$ and $\mathrm{T}$ cells, blocks early B cell development when expressed prematurely. Proc Natl Acad Sci USA 104: 7080-7085, 2007.

34. Fazi F, Rosa A, Fatica A, et al: A minicircuitry comprised of microRNA-223 and transcription factors NFI-A and C/EBPalpha regulates human granulopoiesis. Cell 123: 819-831, 2005.

35. Enver T and Greaves M: Loops, lineage, and leukemia. Cell 94: 9-12, 1998

36. Petersen BE, Goff JP, Greenberger JS and Michalopoulos GK: Hepatic oval cells express the hematopoietic stem cell marker Thy-1 in the rat. Hepatology 27: 433-445, 1998.

37. Masson NM, Currie IS, Terrace JD, Garden OJ, Parks RW and Ross JA: Hepatic progenitor cells in human fetal liver express the oval cell marker Thy-1. Am J Physiol Gastrointest Liver Physiol 291: G45-G54, 2006.

38. Chang J, Nicolas E, Marks D, et al: miR-122, a mammalian liver-specific microRNA, is processed from hor mRNA and may downregulate the high affinity cationic amino acid transporter CAT-1. RNA Biol 1: 106-113, 2004.

39. Farber E: Similarities in the sequence of early histological changes induced in the liver of the rat by ethionine, 2-acetylaminofluorene, and 3'-methyl-4-dimethylaminoazobenzene. Cancer Res 16: $142-148,1956$
40. Menthena A, Deb N, Oertel M, et al: Bone marrow progenitors are not the source of expanding oval cells in injured liver. Stem Cells 22: 1049-1061, 2004

41. Oh SH, Witek RP, Bae SH, et al: Bone marrow-derived hepatic oval cells differentiate into hepatocytes in 2-acetylaminofluorene/ partial hepatectomy-induced liver regeneration. Gastroenterology 132: 1077-1087, 2007.

42. Wang X, Foster M, Al-Dhalimy M, Lagasse E, Finegold M and Grompe M: The origin and liver repopulating capacity of murine oval cells. Proc Natl Acad Sci USA 100 (Suppl 1): 11881-11888, 2003.

43. Thorgeirsson SS and Grisham JW: Hematopoietic cells as hepatocyte stem cells: a critical review of the evidence. Hepatology 43: 2-8, 2006.

44. Saito Y, Liang G, Egger G, et al: Specific activation of micro RNA-127 with downregulation of the proto-oncogene BCL6 by chromatin-modifying drugs in human cancer cells. Cancer Cell 9: 435-443, 2006

45. Shvarts A, Brummelkamp TR, Scheeren F, et al: A senescence rescue screen identifies BCL6 as an inhibitor of anti-proliferative p19(ARF)-p53 signaling. Genes Dev 16: 681-686, 2002.

46. Uchida N, He D, Friera AM, et al: The unexpected G0/G1 cell cycle status of mobilized hematopoietic stem cells from peripheral blood. Blood 89: 465-472, 1997.

47. Hatfield SD, Shcherbata HR, Fischer KA, Nakahara K, Carthew RW and Ruohola-Baker H: Stem cell division is regulated by the microRNA pathway. Nature 435: 974-978, 2005.

48. Shiomi Y, Masutani C, Hanaoka F, Kimura H and Tsurimoto T: A second proliferating cell nuclear antigen loader complex, Ctf18-replication factor C, stimulates DNA polymerase eta activity. J Biol Chem 282: 20906-20914, 2007 